\title{
NEWS
}

\section{Production and Consumption: Textile Economy and Urbanisation in Mediterranean Europe 1000-500 BCE (PROCON)}

\author{
Margarita Gleba*, Susanna Harris* and Joanne Cutler*
}

PROCON is a new project hosted by the UCL Institute of Archaeology, funded by a European Research Council starting grant (No. 312603). The aim of the project is to test the hypothesis that textile production and consumption was a significant driving force of the economy and of the creation and perception of wealth in Mediterranean Europe during the period of urbanisation and early urbanism in 1000-500 BCE. The overarching question to be answered is: To what extent did textile production and consumption define the development of productive and commercial activities of early urban Mediterranean societies in the Iron Age?

The past few years have witnessed a major dynamism in the field of archaeological textile research in Europe, as demonstrated by numerous conferences and publications on the topic, as well as the establishment of large-scale interdisciplinary collaborative programmes, such as the Centre for Textile Research (CTR), funded by the Danish National Research Foundation (2005-2015), and the pan-European project 'Clothing and Identities - New Perspectives on Textiles in the Roman Empire' (DressID), funded by the European Union Education, Audiovisual

\footnotetext{
* UCL Institute of Archaeology,

London WC1H OPY, United Kingdom

m.gleba@ucl.ac.uk, susanna.harris@ucl.ac.uk, j.cutler@ucl.ac.uk, https://www.ucl.ac.uk/procon
}

and Culture Executive Agency (2007-2012). The impetus created by these projects has provided an important arena for the development of new research techniques and approaches. From this basis, the necessary next step is to lead this growing field into answering some of the fundamental questions of archaeology, where evidence for textiles has hitherto been virtually unexplored.

It has been convincingly demonstrated that intensive production and consumption of textiles was at the heart of urbanisation throughout the history of the world. The lords of the Inka state extracted heavy tribute of cloth from its peasants, which in turn clothed and sheltered the army, dressed its lords and citizens and filled its storehouses. In 18th-century England, the Industrial Revolution was fuelled by the desire of the nobility and aspiring middle classes to invest in cloth and clothing, with its chance for self-promotion and political investiture. In the ancient past a similar pattern is recognisable in the emergence of the Bronze Age urban state centres of Mesopotamia and the Aegean. There, early written state archives provide abundant evidence of the importance of textile production and consumption in the formation of the political systems synonymous with urbanisation. Archaeologists have focused particular attention on the floruit of urbanism in the 1st millennium BCE in ancient Greece, Italy and Spain (Osborne 


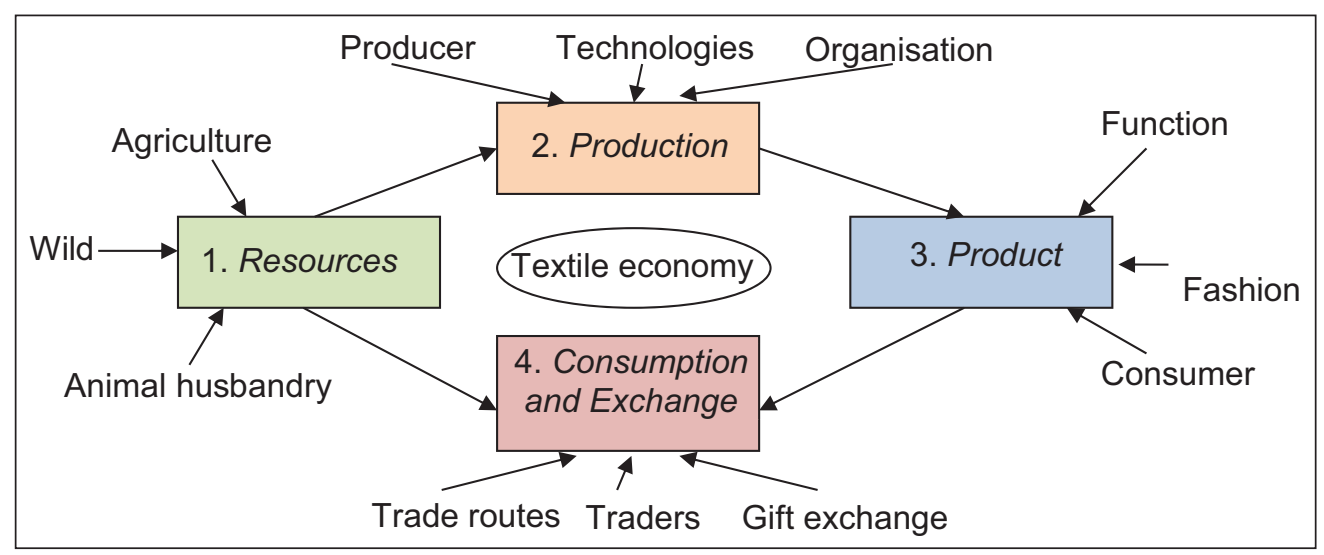

Fig. 1: PROCON project structure, encompassing the chaîne opératoire of textile economy: Resources; Production; Product; and Consumption and Exchange.

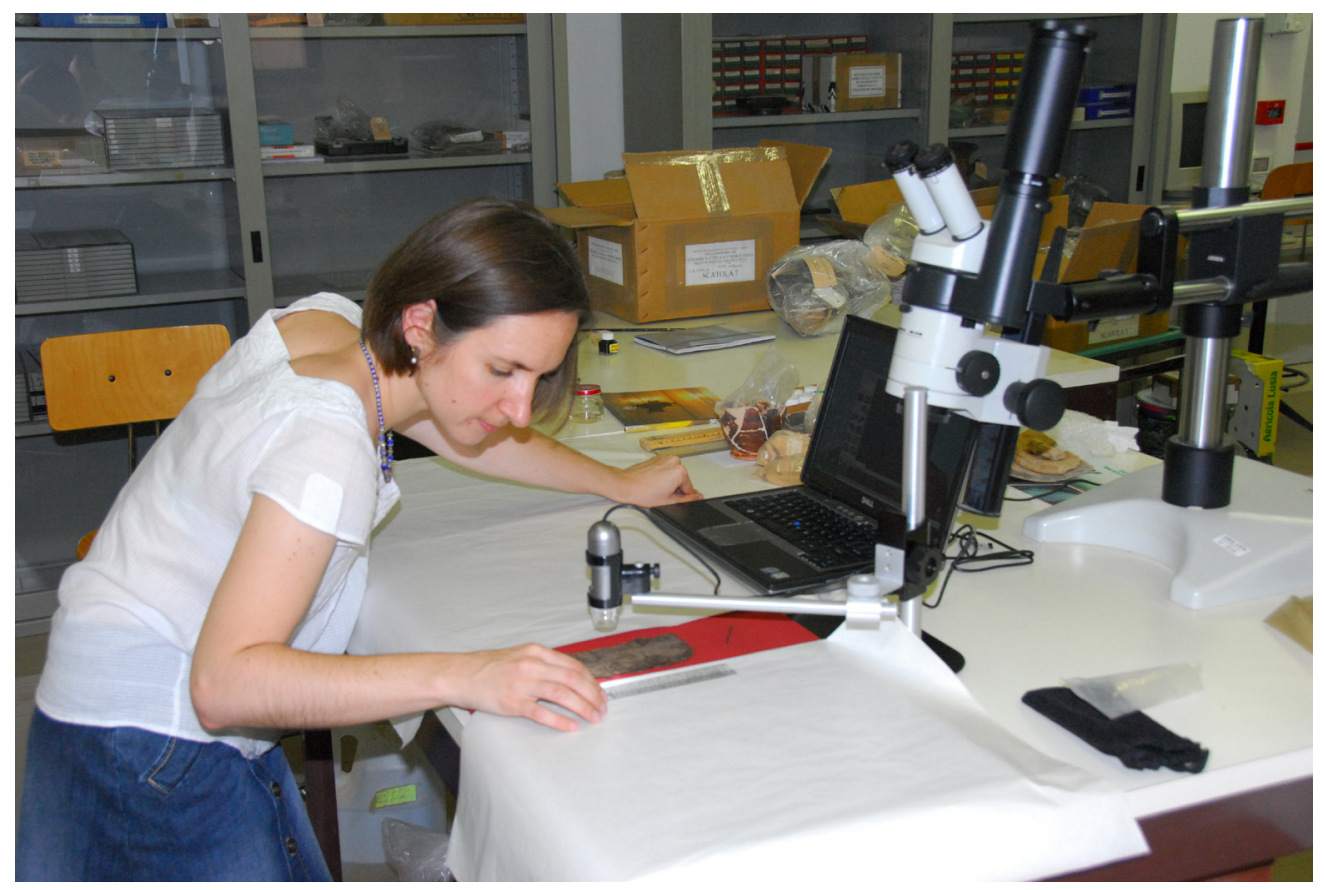

Fig. 2: Studying archaeological textiles using digital microscopy at the National Archaeological Museum of Adria, Italy (photo: Eugene Kokorin).

and Cunliffe, 2005). Yet, despite the promising early evidence for the influence of textiles in the Bronze Age eastern Mediterranean, the role of textiles in the formation of these Iron Age Mediterranean urban centres is largely unexplored.

The focus of the PROCON project is on the significance of the production and con- sumption of textiles for the development of city-states (as clothing, elite regalia, trade and exchange items) and the implications of this for other aspects of the economy, such as the use of farm land, labour resources and the development of urban lifestyle. This aim is achieved by addressing the following research questions: how was 
this production and consumption organised; where did the various resources come from; what were the technologies used; and what was the level of organisation? Who was involved in textile production and consumption? What was the quality and quantity of textiles produced, and how did they change over time in response to urban consumer demands?

In exploring these questions the project not only follows a functional approach, but also considers the value ascribed to these goods and the customs that came with them. The questions outlined above lead to the following objectives for the PROCON project:

1. To evaluate the availability and the degree of exploitation of the various resources for textile production;

2. To assess the technological and organisational parameters of textile production;

3. To explore the consumption of textiles as clothing and utilitarian goods, and to trace the increased demand both for clothing, through changes in fashion and in wealth accumulation, and for sail cloth, with increased mobility;

4. To identify the modes, means and directions (through time and space) of the resource, of the technology and of textile consumption and exchange;

5. On the basis of the above, to provide a new reading of economic history for the period and area under consideration that sees textile production and consumption as a major economic factor during the urbanisation of Early Iron Age Mediterranean Europe.

Using established and novel approaches to textile research, the project results aim to change the landscape of urbanisation research by providing new data sets demonstrating textile production and consumption as major economic and social factors. This project is unique in that it takes developments in a specialist research field (textile archaeology) and applies them to modelling the dynamics behind the broader phenomenon of urbanisation in Europe.

In terms of scale, project PROCON is concerned with broad patterns and adopts a Mediterranean-wide rather than a regional perspective, along with recent scholarship on the 1st-millennium BCE Mediterranean (Vlassopoulos, 2007; Riva, 2010). In doing so, the project explores similarities and differences between the different regions as they followed their trajectories towards urbanisation. The economy of textile production is furthermore conceived as a network that stimulated the mobility of goods, people, ideas and technologies in the context of developing urbanisation.

The project structure thus encompasses four research strands within the operational sequence (chaîne opératoire) of textile economy: Resources; Production; Product; and Consumption and Exchange (Fig. 1). The project is highly interdisciplinary and will draw on methods from the fields of archaeology, biology, geology, chemistry, art history and classics, examining archaeological textiles (Figs 2-5), textile tools (Fig. 6), palaeoenvironmental remains, iconographic and written sources. The planned research will result in a major step forward in our understanding of the economic and social role of textiles in ancient societies.

\section{References}

Osborne, R and Cunliffe, B (eds) 2005 Mediterranean Urbanisation 800-600 BC. Oxford: Oxford University Press/British Academy.

Riva, C 2010 The Urbanisation of Etruria: Funerary Practices and Social Change, 700-600 BC. Cambridge: Cambridge University Press.

Vlassopoulos, K 2007 Unthinking the Greek Polis: Ancient Greek History. Cambridge: Cambridge University Press. 


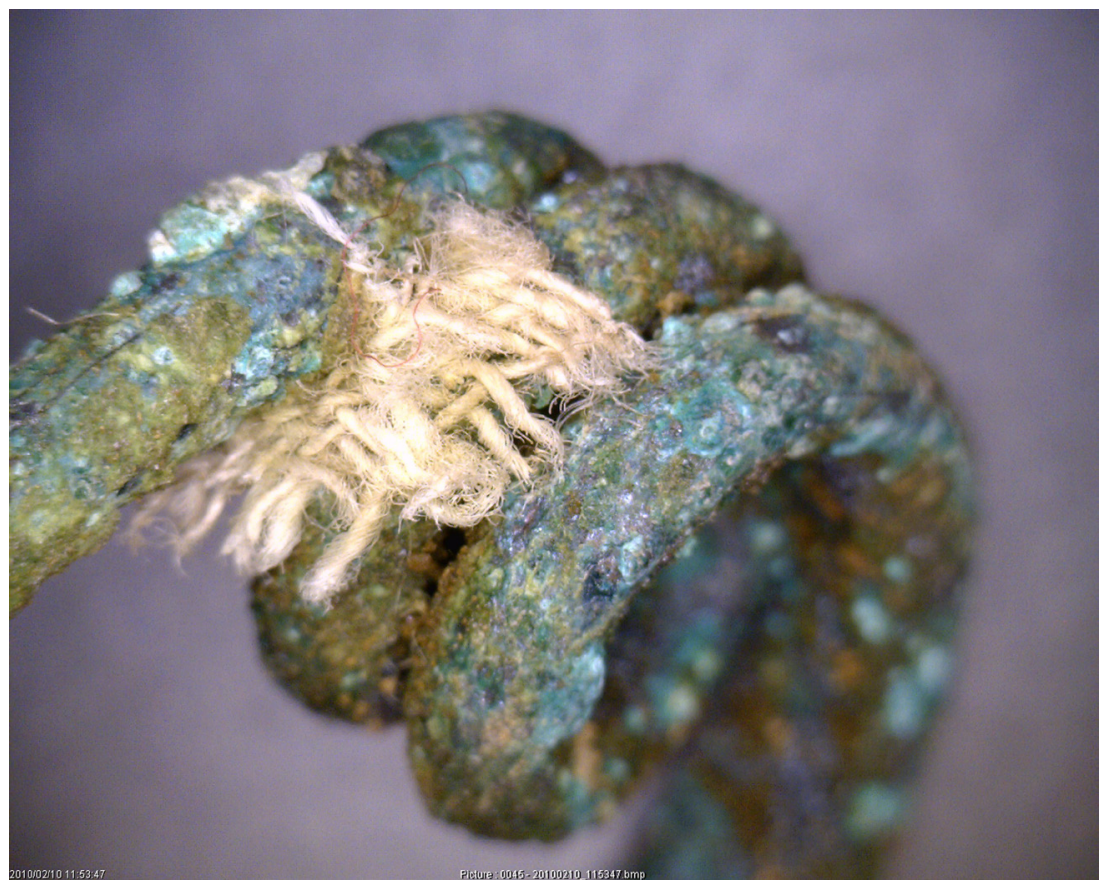

Fig. 3: Archaeological textile preserved on a 6th-century BCE bronze fibula from central Italy; whereas organically preserved textiles are generally rare on northern Mediterranean Iron Age sites, small fragments do survive under special conditions (micrograph: Margarita Gleba).

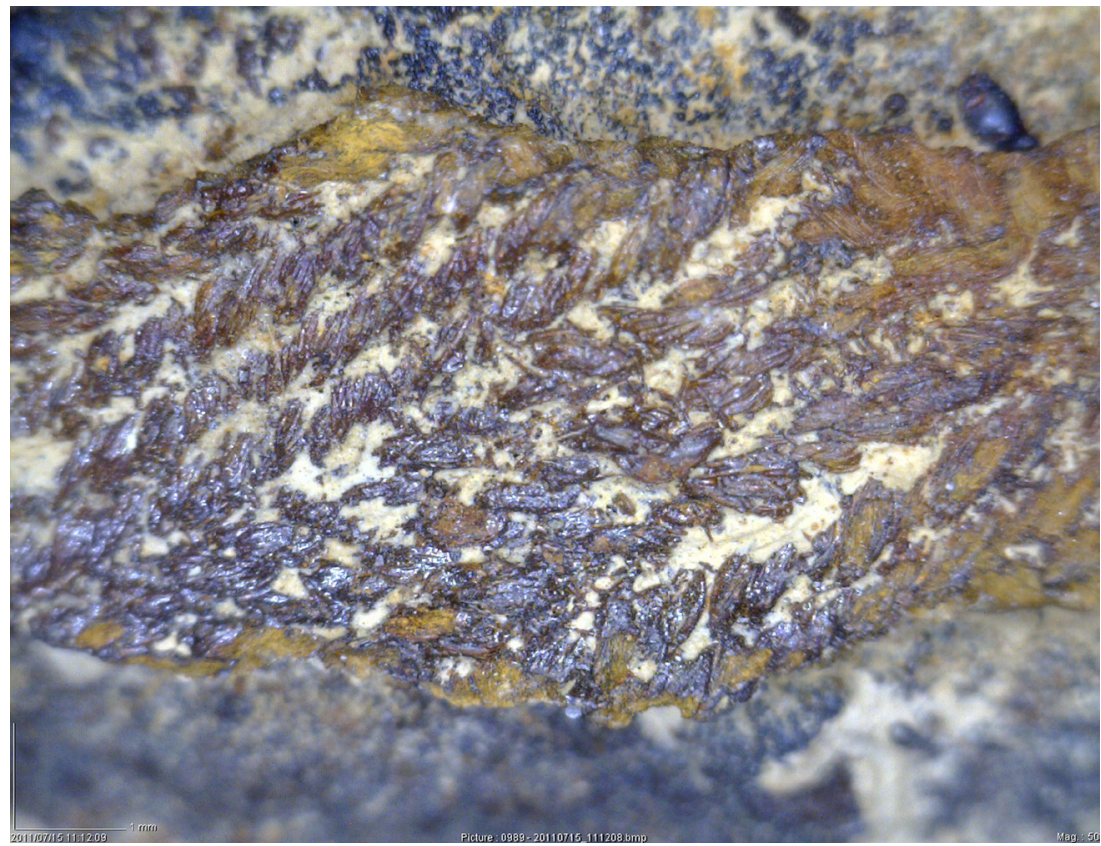

Fig. 4: Mineralised textile preserved on a 7th-century BCE iron fibula from central Italy; even when minute, such traces provide important information about the technical aspects of the original textile, and what it was made of (micrograph: Margarita Gleba). 


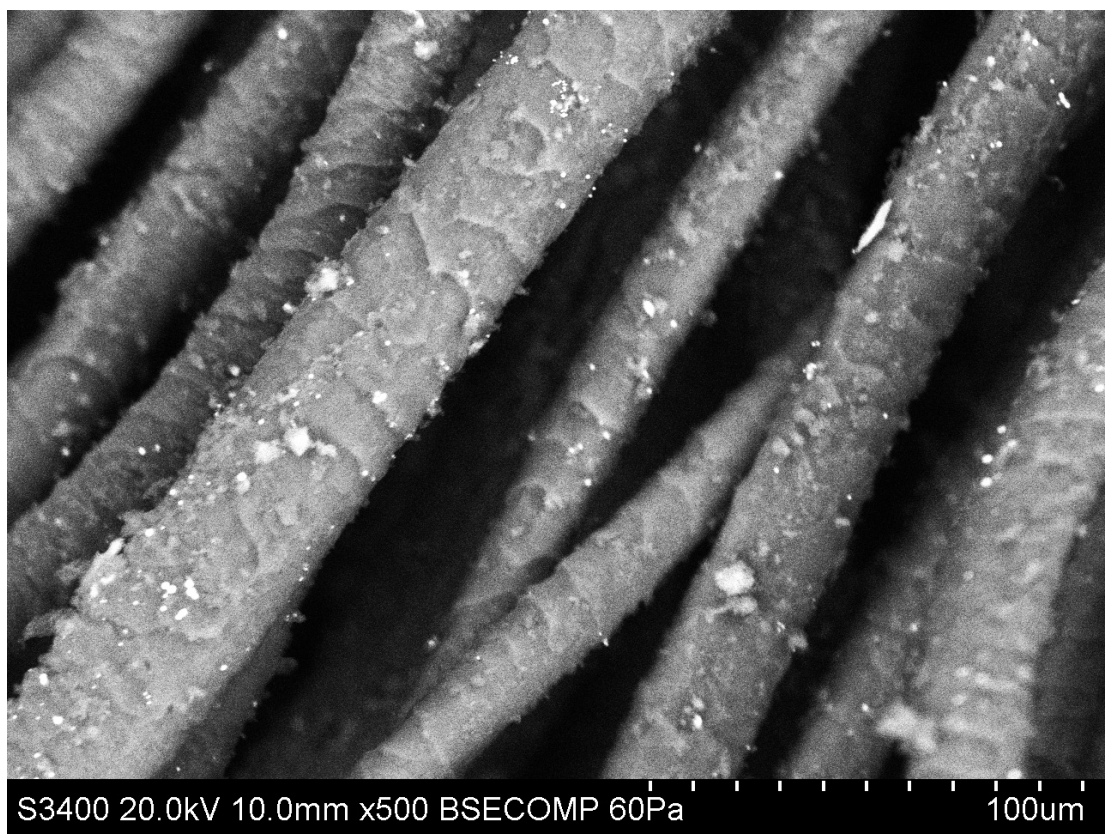

Fig. 5: Scanning Electron Microscope image of an archaeological wool fibre from a 6th-century BCE textile from northern Italy; wool quality analysis based on fibre diameter measurements is important for tracing the development of wool and sheep (image: Margarita Gleba).

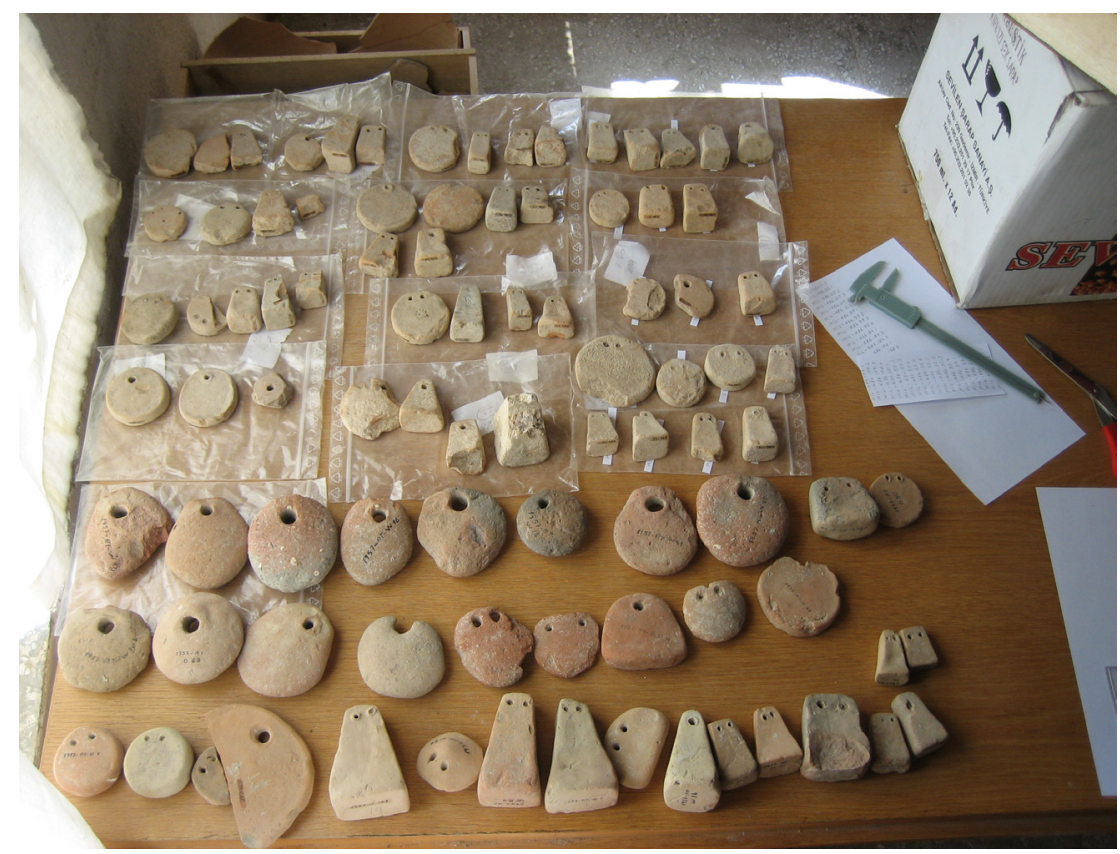

Fig. 6: Statistical analysis of textile tools provides important information about the textile types that they were used to make, with contextual data allowing conclusions about the organisation of production; loom-weights from Miletos, Turkey, dating to the Bronze AgeHellenistic period (photo: Margarita Gleba). 
How to cite this article: Gleba, M, Harris, S and Cutler J 2013 Production and Consumption: Textile Economy and Urbanisation in Mediterranean Europe 1000-500 BCE (PROCON).

Archaeology International, No. 16 (2012-2013): 54-58, DOI: http://dx.doi.org/10.5334/ai.1602

Published: 24 October 2013

Copyright: ๑ 2013 The Author(s). This is an open-access article distributed under the terms of the Creative Commons Attribution 3.0 Unported License (CC-BY 3.0), which permits unrestricted use, distribution, and reproduction in any medium, provided the original author and source are credited. See http://creativecommons.org/licenses/by/3.0/

] $\mathbf{u}$ Archaeology International is a peer-reviewed open access journal published by Ubiquity Press 